\title{
The Gah-PLCD1 signaling axis drives metastatic progression in triple-negative breast cancer
}

Shang-Pen Huang ${ }^{1}$, Pei-Yao Liu', Chih-Jung Kuo ${ }^{2}$, Chi-Long Chen ${ }^{1,3}$, Wei-Jiunn Lee ${ }^{4,5}$, Yu-Hui Tsai ${ }^{6}$ and Yuan-Feng Lin ${ }^{1^{*}}$

\begin{abstract}
Background: Distant metastasis of triple-negative breast cancer (TNBC) to other organs, e.g., the lungs, has been correlated with poor survival rates among breast cancer patients. Therefore, the identification of useful therapeutic targets to prevent metastasis or even inhibit tumor growth of TNBC is urgently needed. Gah is a novel GTP-binding protein and known as an inactive form of calcium-dependent tissue transglutaminase. However, the functional consequences of transamidating and G-protein activities of tissue transglutaminase in promoting cancer metastasis are still controversial.
\end{abstract}

Methods: Kaplan-Meier analyses were performed to estimate the prognostic values of Gah and PLC $\delta 1$ by utilizing public databases and performing immunohistochemical staining experiments. Cell-based invasion assays and in vivo lung colony-forming and orthotropic lung metastasis models were established to evaluate the effectiveness of interrupting the protein-protein interaction (PPI) between Gah and PLC $\delta 1$ in inhibiting the invasive ability and metastatic potential of TNBC cells.

Results: Here, we showed that the increased level of cytosolic, not extracellular, Gah is a poor prognostic marker in breast cancer patients and correlates with the metastatic evolution of TNBC cells. Moreover, clinicopathological analyses revealed that the combined signature of high Gah/PLC $\delta 1$ levels indicates worse prognosis in patients with breast cancer and correlates with lymph node metastasis of ER-negative breast cancer. Blocking the PPI of the Gah/PLC $\delta 1$ complex by synthetically myristoylated PLC $\delta 1$ peptide corresponding to the Gah-binding interface appeared to significantly suppress cellular invasiveness in vitro and inhibit lung metastatic colonies of TNBC cells in vivo.

Conclusions: This study establishes Gah/PLC 11 as a poor prognostic factor for patients with estrogen receptor-negative breast cancers, including TNBCs, and provides therapeutic value by targeting the PPI of the Gah/PLC81 complex to combat the metastatic progression of TNBCs.

Keywords: Gah, Metastasis, PLC 81 , Protein-protein interaction, Triple-negative breast cancer

\footnotetext{
* Correspondence: d001089012@tmu.edu.tw

${ }^{1}$ Graduate Institute of Clinical Medicine, College of Medicine, Taipei Medical

University, 250 Wu-Hsing Street, 110 Taipei, Taiwan

Full list of author information is available at the end of the article
}

\section{Biomed Central}

(c) The Author(s). 2017 Open Access This article is distributed under the terms of the Creative Commons Attribution 4.0 International License (http://creativecommons.org/licenses/by/4.0/), which permits unrestricted use, distribution, and reproduction in any medium, provided you give appropriate credit to the original author(s) and the source, provide a link to the Creative Commons license, and indicate if changes were made. The Creative Commons Public Domain Dedication waiver (http://creativecommons.org/publicdomain/zero/1.0/) applies to the data made available in this article, unless otherwise stated. 


\section{Background}

Triple-negative breast cancers (TNBCs) are a diverse and heterogeneous group of tumors that lack estrogen and progesterone receptors and HER2 gene amplification. Because they do not express these receptors, hormonal (e.g., tamoxifen) and targeted (e.g., Herceptin) therapies are not effective in treating TNBCs. Moreover, the majority of TNBCs are highly malignant, and only a subgroup responds to conventional chemotherapy with favorable prognosis [1-3]. Therefore, drug resistance and metastatic progression are major clinical issues in the successful treatment of TNBCs. Although high-throughput molecular analyses, including sequencing, pathway analyses, and integrated analyses of alterations at the genomic and transcriptomic levels, have improved our understanding of the molecular alterations involved in TNBC development and progression, the proper use of this knowledge for the rational selection of therapy remains challenging.

Goh is a novel GTP-binding protein that is an inactive form of calcium-dependent tissue transglutaminase; a multifunctional protein that is ubiquitously expressed in various tissues [4]. Goh transmits signals from activated G protein-coupled receptors, e.g., $\alpha 1$-adrenoceptor [5] and follicle-stimulating hormone receptor [6], to phospholipase $C-\delta 1$ (PLC- $\delta 1)$ via protein-protein interactions

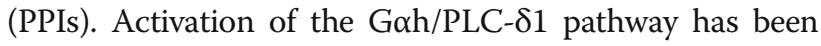
shown to elevate the concentration of intracellular inositol 1,4,5-triphosphate $\left(\mathrm{IP}_{3}\right)$ and calcium [7], both of which are important secondary messengers in signal transduction and promote cell survival, growth, and invasion [8, 9]. In contrast, an abnormal increase in intracellular calcium due to cellular damage or other stressors has been shown to activate the transglutaminase feature of Goh activity to catalyze the crosslinking of cellular proteins and ultimately induce cell death [10]. Recently, Goh overexpression has been observed in breast [11, 12], colon [13], and ovarian cancers [14]; non-small cell lung cancer [15]; and renal cell carcinoma [16] and has been shown to be associated with advanced disease stages and metastatic spread. Importantly, the loss of the GTP-binding, but not transamidating, activity of Goh was shown to inhibit cancer metastasis in malignant tumor cells [17], implying the

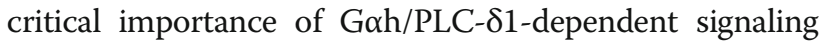
in cancer progression. These findings prompted us to evaluate the feasibility of therapeutic inhibition of the PPI

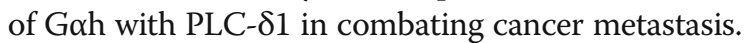

Here, we find that Goh expression is causally associated with the metastatic potential of TNBC cells in vitro and in vivo and is strongly correlated with poor distant metastasis-free survival probability in patients with breast cancer. Notably, loss of the $G$ protein function, but not the transglutaminase activity, abolished the Goh-induced metastatic progression of TNBC cells. Interestingly, blocking the PPI between G $\alpha$ h and PLC- $\delta 1$ using a synthetic peptide blocker corresponding to the binding-interface of Goh effectively inhibited the metastatic progression of TNBC cells in vitro and in vivo. These findings provide a potential new strategy to develop anti-cancer agents for overcoming cancer metastasis.

\section{Methods \\ Cell lines and cell culture condition}

TNBC cell lines MDA-MB-468, MDA-MB-231, and MDA-MB-436 were cultured in Leibovitz's (L-15) medium (Gibco Life Technologies, Grand Island, NY, USA) supplemented with $10 \%$ fetal bovine serum (FBS, Invitrogen) and incubated at $37{ }^{\circ} \mathrm{C}$ with free gas exchange with atmospheric air. TNBC cell lines HCC1143, HCC1599, HCC70, and HCC38 were cultured in RPMI1640 medium (Gibco Life Technologies) with 10\% FBS and incubated at $37{ }^{\circ} \mathrm{C}$ with $5 \% \mathrm{CO}_{2}$. HS578T and 293T cells were cultured in DMEM with 10\% FBS and incubated at $37{ }^{\circ} \mathrm{C}$ with $5 \% \mathrm{CO}_{2}$. All cell lines were obtained from American Type Culture Collection (ATCC). All cells were routinely authenticated on the basis of short tandem repeat (STR) analysis, morphologic, and growth characteristics and mycoplasma detection.

\section{Public database}

Raw data for pathological information and prognostic values of the Goh gene were downloaded from the PrognoScan database (http://www.prognoscan.org/). Datasets with $p$ value $<0.05$ by Cox regression analysis were included in a meta-analysis for Goh gene expression.

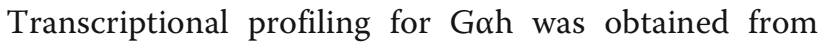
The Cancer Genome Atlas (TCGA) database and subjected to statistical analysis against differential levels of Goh mRNA in the subgroups. Kaplan-Meier analysis

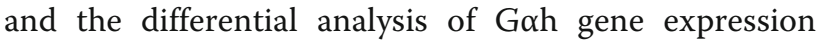
were performed on the SurvExpress website.

\section{In vitro invasion assay}

For invasion assays, Boyden chambers (Neuro Probe, Gaithersburg, MD, USA) were used according to the manufacturer's protocol. Briefly, a polycarbonate membrane (Neuro Probe) was pre-coated with $10 \mu \mathrm{g}$ of human fibronectin (Sigma-Aldrich, St Louis, MO, USA) on the lower side and Matrigel on the upper side. Cells $\left(1.5 \times 10^{4}\right)$ were seeded in the top chamber in $50 \mu \mathrm{l}$ of low-serum medium $(0.1 \%$ FBS $)$ containing drugs or DMSO. After $16 \mathrm{~h}$, stationary cells were removed from the top surface of the membrane, whereas the migrated cells on the bottom surface of the membrane were fixed in $100 \%$ methanol and stained with $10 \%$ Giemsa solution (Merck Biosciences, Mendota Heights, MN, USA) for $1 \mathrm{~h}$. The invaded cells were counted under a light 
microscope $(\times 400$, ten random fields from each well). All experiments were performed in triplicate.

\section{Western blot analysis}

Proteins $(100 \mu \mathrm{g})$ were boiled for $5 \mathrm{~min}$ in SDS sample buffer (62.5 mM Tris [pH 6.7], 1.25\% SDS, 12.5\% glycerol, and $2.5 \% \beta$-mercaptoethanol) and separated on $10 \%$ SDSPAGE gels. After transferring to PVDF membranes, the proteins were incubated with antibodies against Goh (GeneTex, Hsin-Chu, Taiwan), PLC- $\delta 1$ (GeneTex), or GAPDH (AbFrontier, San Diego, CA, USA). The immunoreactive bands were visualized using an enhanced chemiluminescence system (GE Healthcare, Pittsburgh, PA, USA).

\section{GTP-binding assay}

Membrane proteins $(100 \mu \mathrm{g})$ were diluted with $500 \mu \mathrm{l}$ of 5 -fold diluted buffer B (prepared as instructed by the manufacturer of the membrane extraction kit) containing $1 \mathrm{mM}$ sodium orthovanadate, $1 \mathrm{mM}$ dithiothreitol (DTT), and $4 \%$ protease inhibitor cocktail (Merck Biosciences). The membrane proteins were then absorbed into GTP-agarose (Sigma-Aldrich) overnight at $4{ }^{\circ} \mathrm{C}$. The GTP-agarose-absorbed complexes/proteins were subsequently analyzed by SDS-PAGE/Western blotting using antibodies against PLC- $\delta 1$ or G $\alpha$.

\section{In situ tTG activity assay}

A $50 \mu \mathrm{l}$ aliquot of cell homogenate proteins $(10 \mu \mathrm{g})$ in coating buffer (50 mM Tris- $\mathrm{HCl}[\mathrm{pH} 7.4], 150 \mathrm{mM}$ $\mathrm{NaCl}, 5 \mathrm{mM}$ EDTA, and $5 \mathrm{mM}$ EGTA) was added to each well of a 96-well ELISA plate (Apogent, Portsmouth, NH, USA) and was incubated at $4{ }^{\circ} \mathrm{C}$ overnight. To block the coated wells, a $200 \mu \mathrm{l}$ aliquot of 5\% BSA, $0.01 \%$ Tween $20,0.01 \%$ SDS in borate-buffered saline (BBS) was added. After an additional $2 \mathrm{~h}$ of incubation at $37{ }^{\circ} \mathrm{C}$, the plate was rinsed once with $1 \% \mathrm{BSA}$ and $0.01 \%$ Tween-20 in BBS. To each well, $100 \mu$ of HRPconjugated streptavidin (Southern Biotech, Birmingham, AL, USA) (1:1000) in 1\% BSA and $0.01 \%$ Tween-20 in BBS was added, followed by incubation for another $1 \mathrm{~h}$ at room temperature (RT). After the wells were rinsed four times with $1 \%$ BSA and $0.01 \%$ Tween-20 in BBS, the specimen in each well was incubated with $200 \mu \mathrm{l}$ of TMB substrate (Sigma-Aldrich) for 10-20 min at RT. The reaction was stopped with $50 \mu \mathrm{l}$ of $3 \mathrm{~N} \mathrm{HCl}$, and the absorbance at $450 \mathrm{~nm}$ was measured using a microplate spectrophotometer.

\section{Peptide synthesis}

TIPWNSLKQGYRHVHLL, a peptide corresponding to the PLC- $\delta 1$ amino acid sequence from 720 to 736 , was synthesized with or without myristoylation at the
$\mathrm{N}$-terminus and purified to approximately 95\% (Mission Biotech, Taipei, Taiwan). Ten millimolar synthetic peptide was dissolved in 1 part of $0.1 \%$ trifluoroacetic acid in dd $-\mathrm{H}_{2} \mathrm{O}$ mixed with 1 part $0.1 \%$ trifluoroacetic acid in acetonitrile, aliquoted, and kept at $-70{ }^{\circ} \mathrm{C}$ as a stock solution.

\section{Plasmid construction}

The genes encoding G $\alpha \mathrm{h}$ and PLC- $\delta 1$ were amplified from human cDNA (Invitrogen) using standard polymerase chain reaction (PCR) with paired primers (Additional file 1: Table S1) and sub-cloned into the pLAS3w/Ppuro, pLAS3w/Pbsd, or pIRES2-EGFP vector. The Goh-containing pIRES2-EGFP plasmid was used as a DNA template for site-directed and deletion mutagenesis. PCR for site-directed mutagenesis was performed with paired primers (Additional file 1: Table S1) using a pfu polymerase kit (Stratagene, La Jolla, CA, USA) (for R580A) or primer extension method [18] (for W241A). The PCR products were treated with Dpn1 endonuclease (New England BioLabs, Hitchin, Hertfordshire, UK) to digest the methylated parental DNA template. For the

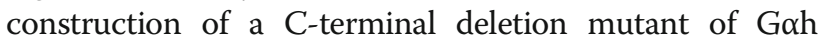
( $\Delta 657-687)$, a Gah-containing pIRES2-EGFP plasmid was used as the template to amplify the target sequence using paired primers (Additional file 1: Table S1). The two PCR products were subsequently digested with NheI and EcoRI and then ligated into pLAS3w/Pbsd. The identities of individual clones were verified via doublestrand plasmid sequencing.

\section{Preparation and infection of lentiviral particles}

All lentiviral vectors, including pLAS3w/Ppuro and pLAS3w/Pbsd and derivatives of shRNA vector (obtained from the National RNAi Core Facility Platform in Taiwan), were transfected into the packaging cell line 293T along with pMD.G and pCMVAR8.91 plasmids using a calcium phosphate transfection kit (Invitrogen). After incubation for $48 \mathrm{~h}$, the viral supernatants were collected and transferred to target cells, and the infected cells were cultured in the presence of puromycin and blasticidin (Calbiochem, San Diego, CA, USA) at $5-10 \mu \mathrm{g} / \mathrm{ml}$ in order to select the stably transfected cells.

\section{Animal experiments}

NOD/SCID mice were obtained from the National Laboratory Animal Center in Taiwan and maintained in compliance with the institutional policy. All animal procedures were approved by the Institutional Animal Care and Use Committee at Taipei Medical University.

For the in vivo lung metastatic colonization assay, cells were implanted into mice through tail vein injection at a 
concentration of $1 \times 10^{6}$ cells $/ 100 \mu \mathrm{l}$ of PBS. The mice were sacrificed, and the lungs were dissected for histological analyses at the endpoint. The metastatic lung nodules were quantified after $H \& E$ staining using a dissecting microscope.

For orthotopic lung metastasis of breast cancer, GFP/ luciferase-expressing MDA-MB-231 cells $\left(5 \times 10^{5}\right)$, which were established by virally transducing cells with an EF1 promoter-driven firefly luciferase vector and an IRESdriven EGFP vector, were suspended in $50 \mu \mathrm{L}$ of PBS and then were subcutaneously inoculated into the abdominal fat pad of each mouse. In vivo tumor images were captured with an IVIS imaging system (Caliper Life Sciences, Alameda, CA, USA) to measure the signal intensity from the GFP/luciferase vector. The mice were humanely sacrificed at the end of the experiments, and lungs were obtained for histological analyses. The tumors at the primary sites were removed for weight measurement.

\section{Clinical samples and ethics statement}

The breast cancer tissues used in this study were from Wan Fang Hospital managed by Taipei Medical University (TMU). Patient information, including gender, age, and histopathological diagnoses, was collected. The surgical specimens had been fixed in formalin and embedded in paraffin before being archived. We used the archived specimens for IHC staining. Follow-up of patients was carried out for up to 60 months. A four-point staining intensity scoring system was devised to determine the relative expression of Goh and PLC- $\delta 1$ in the cancer specimens; the staining intensity score ranged from 0 (no expression) to 3 (maximal expression). All of the IHC staining results were reviewed and scored independently by two pathologists. The study was carried out with the approval of the Institutional Review Boards and with permission from the ethics committees of the institutions involved (TMU-IRB 99049).

\section{Immunohistochemical staining analysis}

Paraffin-embedded tumor sections $(3 \mu \mathrm{m}$ thick) were heated and deparaffinized using xylene and then were rehydrated in a graded series of ethanol with a final wash in tap water. Antigen retrieval was performed with a target retrieval solution (DAKO, Woodbridge, VA, USA) in a decloaking chamber (Biocare Medical, Concord, CA, USA). Endogenous peroxidase activity was quenched by hydrogen peroxide. The sections were then incubated

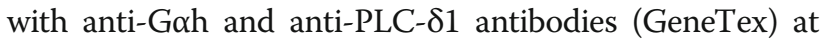
$4{ }^{\circ} \mathrm{C}$ overnight. The Vectastain $\mathrm{ABC}$ peroxidase system (Vector Laboratories, Burlingame, CA, USA) was used to detect the reaction products.

\section{Statistical analysis}

SPSS 17.0 software (Informer Technologies, Roseau, Dominica) was used to analyze statistical significance. Paired $t$ test was utilized to compare Gah gene expression in the cancer tissues and corresponding normal tissues. Pearson's test was performed to estimate the association between mRNA and protein expression of Gah and PLC- $\delta 1$ by RNA-sequencing and IHC, respectively. Evaluation of survival probabilities were determined by Kaplan-Meier analysis and log-rank test. One-way ANOVA with Tukey's test was used to estimate the difference in lung colonies and tumor weights in the animal experiments. The Mann-Whitney $U$ test was used to analyze the non-parametric data. $p$ values $<0.05$ in all analyses were considered statistically significant.

\section{Results}

Gah upregulation predicts a poor probability of distant metastasis-free survival in breast cancer patients

To evaluate the clinical relevance of Goh overexpression $(\mathrm{OE})$, we performed a global prognostic meta-analysis for the Gah gene (TGM2) on microarray data from clinical cohorts with different cancer types using PrognoScan [19]. The data demonstrated that the upregulation of Goh correlated with poor prognosis as judged by an increased hazard ratio in patients with bladder, brain, breast, lung, or ovarian cancers but not in patients with blood or colorectal cancer (Fig. 1a). Although the lower expression of Gah transcripts referred to a poor outcome in a few studies, the clinical cohorts with highly invasive breast and lung cancers that expressed an increased level of Goh transcripts accounted for the reduction in the probabilities of distant metastasis or recurrence-free survival (Fig. 1b). Based on these findings, this study was focused on investigating the oncogenic effect of Goh overexpression (OE) on promoting the metastatic progression of breast cancer.

Next, we examined the transcriptional profiles of Gah in clinical tissues from breast cancer patients using The Cancer Genome Atlas (TCGA) database [20]. The data showed that the transcriptional activity of Goh in TNBC and metastatic breast cancer was higher than that of the non-tumor and non-TNBC tissues (Fig. 1c, d). Moreover, the transcriptional activity of Gah appeared to be enhanced in cancer tissues compared to the adjacent normal tissues derived from breast cancer patients (Fig. 1e).

To validate the clinical relevance of Goh expression in the metastatic evolution of TNBCs, we evaluated the prognostic significance of Goh-OE in the lung metastasis of an estrogen receptor (ER)-negative breast cancer cohort (GSE5327) from the SurvExpress database. The data showed that Gah-OE indicated a poor probability of lung metastasis-free survival (Fig. 1f) and was notable 

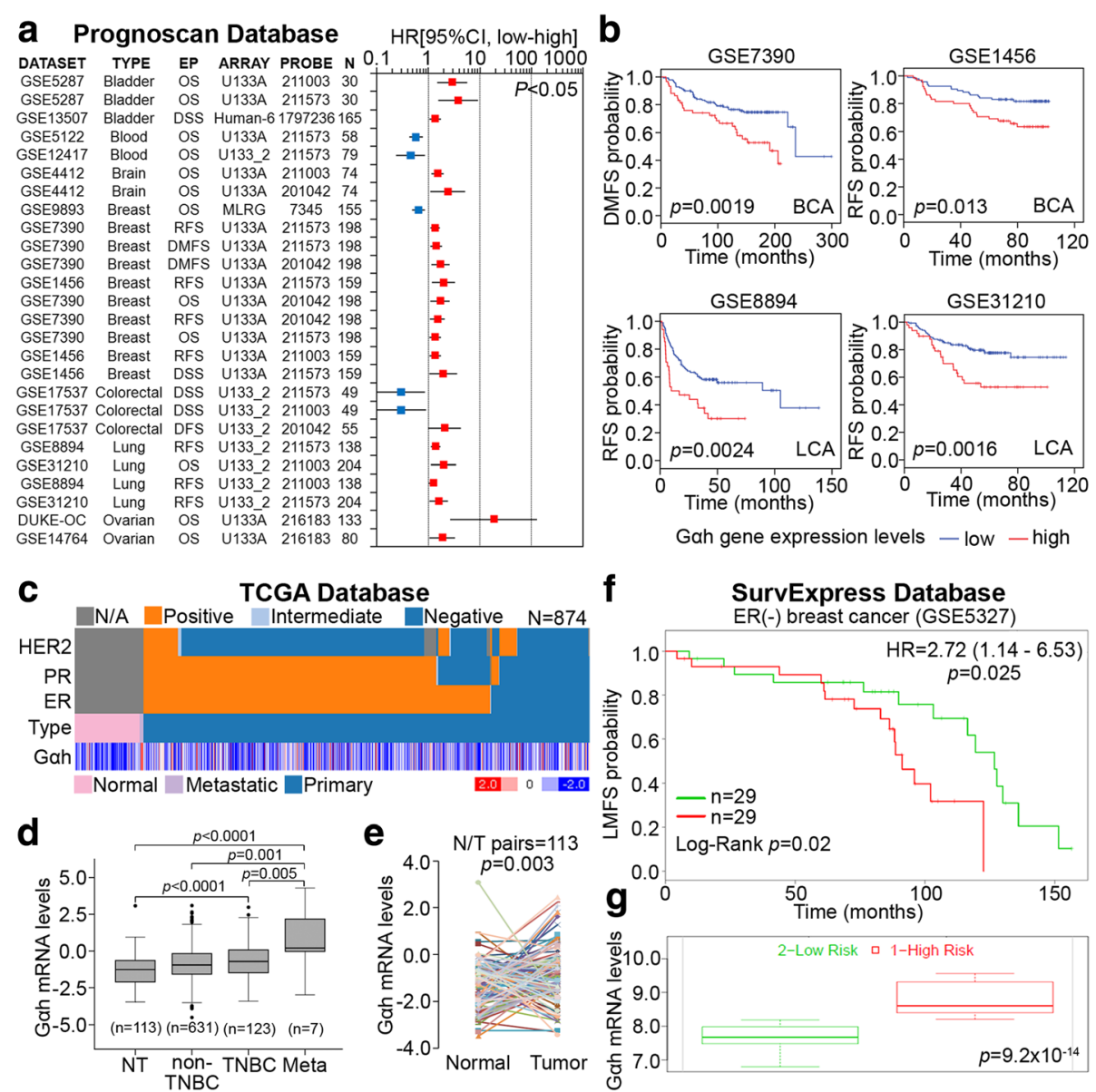

Fig. 1 Gah-OE correlates with the metastatic progression of breast cancer. a A global meta-analysis of the expression of Gah gene (TGM2) in clinical cohorts with different cancer types using the PrognoScan database. EP denotes endpoint, $N$ indicates patient number, and $P$ represents the statistical significance by Cox regression. b Kaplan-Meier plot for Gah gene expression from GSE7390, GSE1456, GSE8894, and GSE31210 datasets in the PrognoScan database to evaluate the probability of distant metastasis-free survival (DMSF) or recurrence-free survival (RFS). c Heatmap of Gah gene expression in normal tissues and metastatic and primary tumor tissues derived from clinical breast cancer patients in TCGA database. $\mathbf{d}$ Gah gene expression in normal tissues and tumor tissues derived from patients with non-TNBC, TNBC, and metastatic breast cancer in TCGA database. e Gah gene expression in paired normal and tumor tissues derived from breast cancer patients in TCGA database. $\mathbf{f}$ and $\mathbf{g}$ Kaplan-Meier analysis of Gah gene levels (f) and Gah gene transcriptional activity ( $\mathbf{g}$ ) in cohorts with low and high risk of lung metastasis in estrogen receptor (ER)-negative breast cancer patients from the GSE5327 dataset in the SurvExpress database

in breast cancer tissues derived from patients with a higher risk of lung metastasis (Fig. 1g).

\section{Gah overexpression promotes the metastatic potential of TNBC cells}

To investigate the association between the expression of Gah and the metastatic potential of TNBC, we performed immunoblotting to survey the endogenous level of Goh in a panel of TNBC cell lines, including BT-20, BT549, HCC38, HCC1806, HCC1937, and MDA-MB231. HCC1806 cells expressed the lowest Goh level, whereas MDA-MB-231 cells displayed a relatively high level of Goh expression (Fig. 2a). Accordingly, invasion assay revealed that HCC1806 cells exhibit a reduced invasive ability, and the MDA-MB-231 cells display an elevated invasive property among the tested TNBC cell lines (Fig. 2b). Statistical analysis showed that the endogenous protein levels of Gah significantly $(p=0.042)$ correlates with cellular invasion ability in the tested TNBC cells (Fig. 2c). To understand if Gah-OE is capable of promoting the invasiveness of TNBC cells, we ectopically expressed Gah in HCC1806 cells (Fig. 2d). The data showed that Goh-OE robustly increased the invasive ability of HCC1806 cells (Fig. 2e). Moreover, Gah-OE appeared to significantly enhance the metastatic colony formation of HCC1806 cells in the lungs after tail vein injection into mice (Fig. 2f-h). 

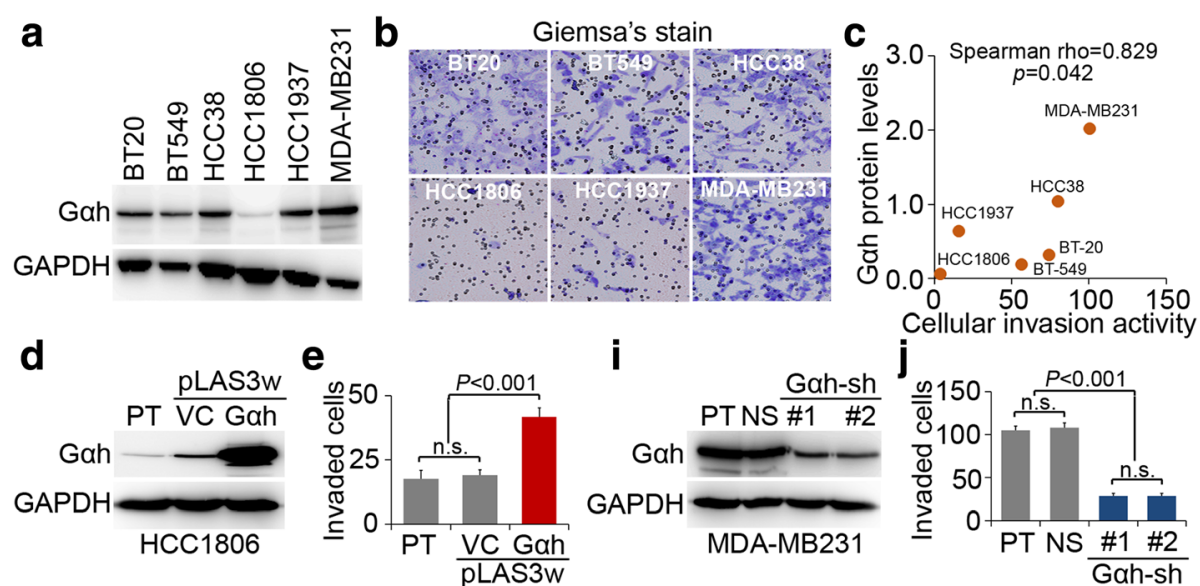

Cellular invasion activity

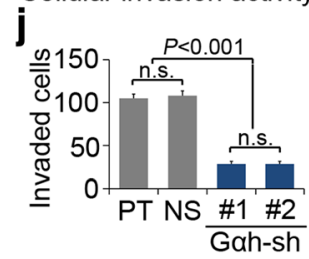

f
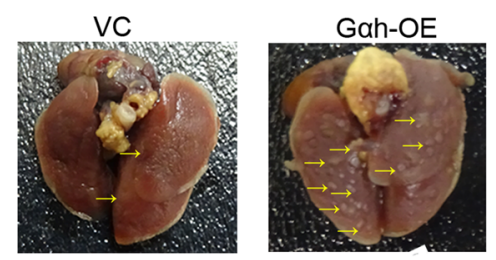

$\mathbf{k}$
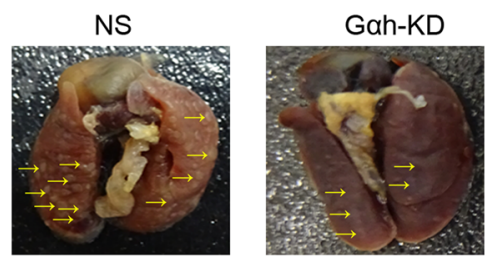

9
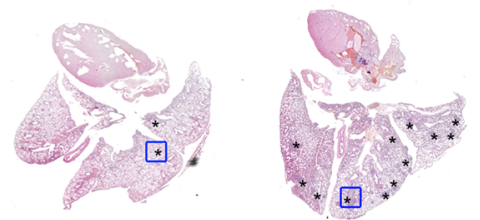

I
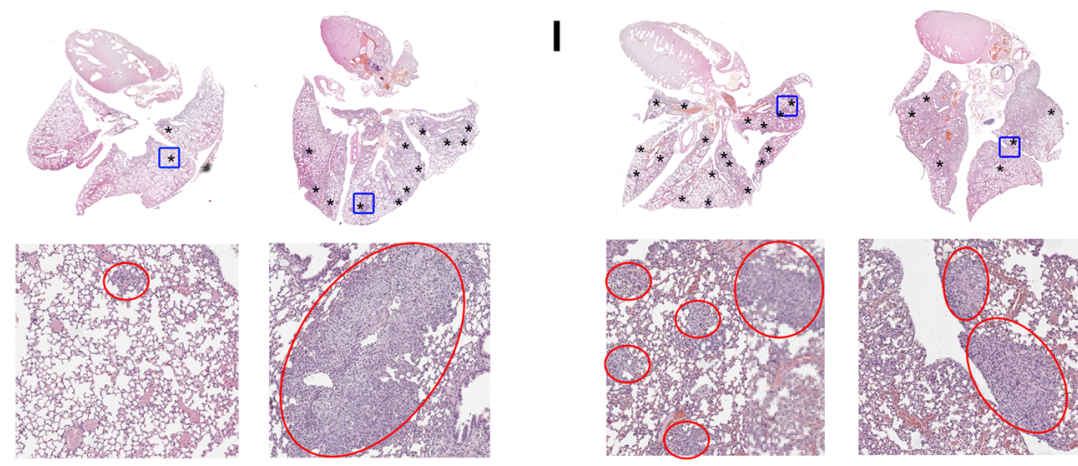

$\mathbf{h}$

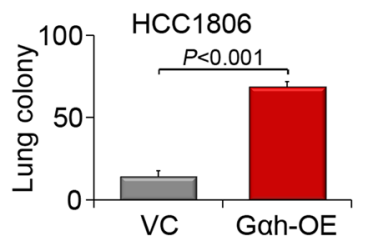

\section{m}
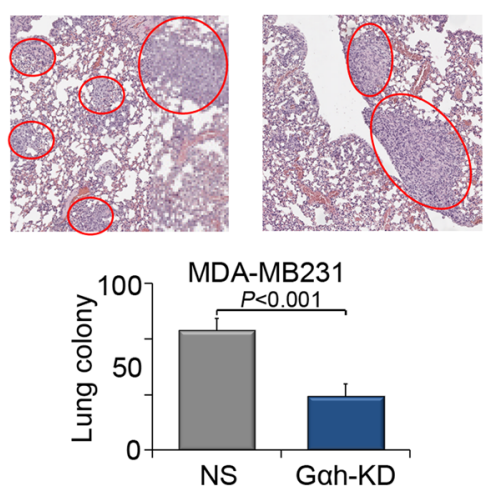

Fig. 2 The upregulation of Gah promotes the metastatic potential of TNBC cells in vitro and in vivo. a Western blot analysis for the endogenous expression of Gah and GAPDH in a panel of TNBC cell lines. $\mathbf{b}$ Giemsa staining for the invaded cells after $16 \mathrm{~h}$ of incubation in a panel of TNBC cell lines. c Correlation between endogenous protein levels of Gah and cellular invasion ability in TNBC cell lines. Statistical significance was analyzed by Spearman's correlation test. $\mathbf{d}$ Western blot analysis for the expression of Gah and GAPDH in parental (PT) HCC1806 cells or HCC1806 cells without (vector control, VC), or with Gah overexpression. e The invaded cells after $16 \mathrm{~h}$ of incubation of the HCC1806 cell variants shown in $\mathbf{d}$. $\mathbf{f}-\mathbf{h}$ Lung colony formation assay of HCC1806 cells without (VC) or with Gah overexpression (Gah-OE). Lungs were obtained from mice $(n=5)$ after 4 weeks of tail vein injection ( $\mathbf{f}$ ) and then were subjected to H\&E staining $(\mathbf{g})$. $\mathbf{h}$ Tumor nodules in the representative images indicated by arrows in $\mathbf{f}$ were counted. $\mathbf{i}$ Western blot analysis for the expression of Gah and GAPDH in parental (PT) MDA-MB-231 cells or MDA-MB-231 cells transfected with non-silencing (NS) or 2 independent Gah-targeting shRNAs. In $\mathbf{d}$ and $\mathbf{i}$, GAPDH was used as the internal control for protein loading. $\mathbf{j}$ The invaded cells after 16 h of incubation from the MDA-MB-231 cell variants shown in $\mathbf{i} . \mathbf{k}-\mathbf{m}$ Lung colony formation assay of MDA-MB-231 cells transfected with NS or Gah-targeting shRNAs. $\mathbf{k}$ Lungs were obtained from mice $(n=5) 4$ weeks after tail vein injection I and then subjected to H\&E staining. $\mathbf{m}$ Tumor nodules in the representative images indicated by arrows in E were counted

Conversely, we performed Gah knockdown (KD) in MDA-MB-231 cells (Fig. 2i) to see if the transcriptional inhibition of Gah could suppress the metastatic potential of TNBCs. Our data showed that silencing Goh expression by two independent shRNA clones dramatically suppresses the invasive ability of MDA-MB-231 cells (Fig. 2j). 
Similarly, Goh-KD appeared to effectively mitigate the metastatic colonization of MDA-MB-231 cells in the lungs of tumor-bearing mice (Fig. $2 \mathrm{k}-\mathrm{m}$ ). These findings demonstrate that Goh-OE is likely correlated with metastatic progression of TNBCs.

\section{Intracellular GTP-binding activity, but not extracellular transglutaminase activity, of Gah dictates the metastatic evolution of TNBCs}

To delineate which Goh activity is required for promoting the metastatic progression of TNBCs, we next performed site-directed mutagenesis to generate Goh constructs with mutations at residues 241 (W to A) and 580 ( $\mathrm{R}$ to A), which have been shown to result in defects in its transamidating and GTP-binding activities, respectively [17]. Our data showed that compared to wild-type Goh, ectopic expression of the W241A mutant abolishes the transamidating, but not GTP-binding, activity of Goh; conversely, the overexpression of R580A mutant inhibits the GTPbinding, but not transamidating, activity of Goh in HCC1806 cells (Fig. 3a, b). Whereas the overexpression of the wild-type and W241A mutant Goh appeared to enhance the invasive ability, ectopic expression of the R580A mutant failed to promote the invasive ability of HCC1806 cells (Fig. 3c, d).

To validate that the GTP-binding activity of Goh is critical for mediating invasive activity of TNBCs, we next reconstituted the expression of wild-type and

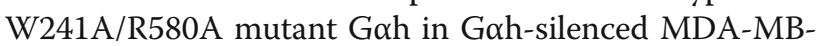
231 cells (Fig. 3e). Our results revealed that restoration of the expression of the wild-type and W241A mutant, but not the R580A mutant, Goh rescues the GTPbinding activity and invasive ability of the Goh-silenced MDA-MB-231 cells (Fig. 3e-h). Since restoring the expression of the transamidating activity-deficient W241A mutant was still incapable of recovering the invasive ability of Gah-KD MDA-MB-231 cells, we concluded that the G protein function of Goh dictates the metastatic evolution of Gah-overexpressing TNBC cells.

\section{The upregulation of cytosolic, not extracellular, Gah} predicts poor prognosis and increased metastatic risk in breast cancer

We next performed immunohistochemical (IHC) staining analysis to examine the protein level and distribution of Goh in clinical specimens of breast cancers. Intriguingly, we found a pronounced accumulation of Goh in either the extracellular matrix (ECM) or the cytosol in a subset of breast cancer tissues (Fig. 4a). Moreover, Goh expression in the ECM and cytosol was significantly inversely correlated in the analyzed breast cancer tissues (Fig. 4a). Whereas increased levels of Goh in the ECM predicted a favorable outcome, the accumulation of Goh in the cytosol predicted a poor prognosis in breast cancer patients (Fig. 4b). In contrast to the signature of high extracellular and low cytosolic Goh expression, low extracellular and high cytosolic Gah levels appeared to be strongly correlated with a worse probability of disease-free survival in breast cancer patients (Fig. 4b). Cox regression analyses of disease-free survival demonstrated that increased levels of cytosolic Goh, the signature of low extracellular/high cytosolic Goh and higher $\mathrm{T}$ and $\mathrm{N}$ stages significantly correlate with an unfavorable hazard ratio, whereas the elevated levels of extracellular Goh serves as a good prognostic factor in a univariate model (Additional file 1: Table S2). Notably, in the multivariate analysis adjusted by the prognostic power of higher $\mathrm{T}$ and $\mathrm{N}$ stages, high cytosolic Gah and the low extracellular/high cytosolic Goh signature remained as an independent risk factors for poor outcome among the studied breast cancer patients (Fig. 4c and Additional file 1: Table S3). Furthermore, in contrast to the high extracellular Goh levels, our data revealed that the high cytosolic Gah levels and the low extracellular/high cytosolic Goh signature closely associates with lymph node metastasis in ER-negative breast cancer (Fig. 4d).

\section{The protein-protein interaction between Gah and PLC $\delta 1$ determines cellular invasion in TNBC cells and serves as a therapeutic target for combating TNBC metastasis}

The coupling of activated Goh to PLC $\delta 1$ signaling cascades has been identified previously [21]. To understand the importance of the protein-protein interaction (PPI) between Goh and PLC $\delta 1$ in Goh-promoted cellular invasion in TNBC cells, we next generated a Goh variant $\left(\Delta 657 \_687\right)$ with deletion of the PLC81-binding interface (between amino acids 657 and 677) (Fig. 5a). Notably, the ectopic expression of the $G \alpha h / \Delta 657 \_687$ mutant did not have any effect, whereas the wild-type $G \alpha h$ increased the invasive ability of HCC1806 cells (Fig. 5b, c). We also synthesized a peptide fragment corresponding to the PLC $\delta 1$ amino acid sequence from 720 to 736, which has been identified previously as the binding-interface of Goh [7], with or without myristoylation (Myr) at the $\mathrm{N}$-terminus (Fig. $5 \mathrm{~d}$ ) in order to facilitate its penetration across the cell membrane. Cell invasion assay showed that the Myr-PLC 81 peptide compared to the unmodified peptide suppressed the invasiveness of MDA-MB-231 cells in a dose-dependent manner (Fig. 5e, f). These findings suggest that the PPI between Goh and PLC $\delta 1$ likely plays a central role in regulating the invasion of TNBC cells.

Moreover, IHC results from serial sections demonstrated that the levels of cytosolic Goh and PLC 1 are positively correlated (Fig. 5g). Similar to the high level of expression of cytosolic Goh, increased protein levels of PLC 11 was identified as poor prognostic factor in patients with breast cancer (Additional file 1: 


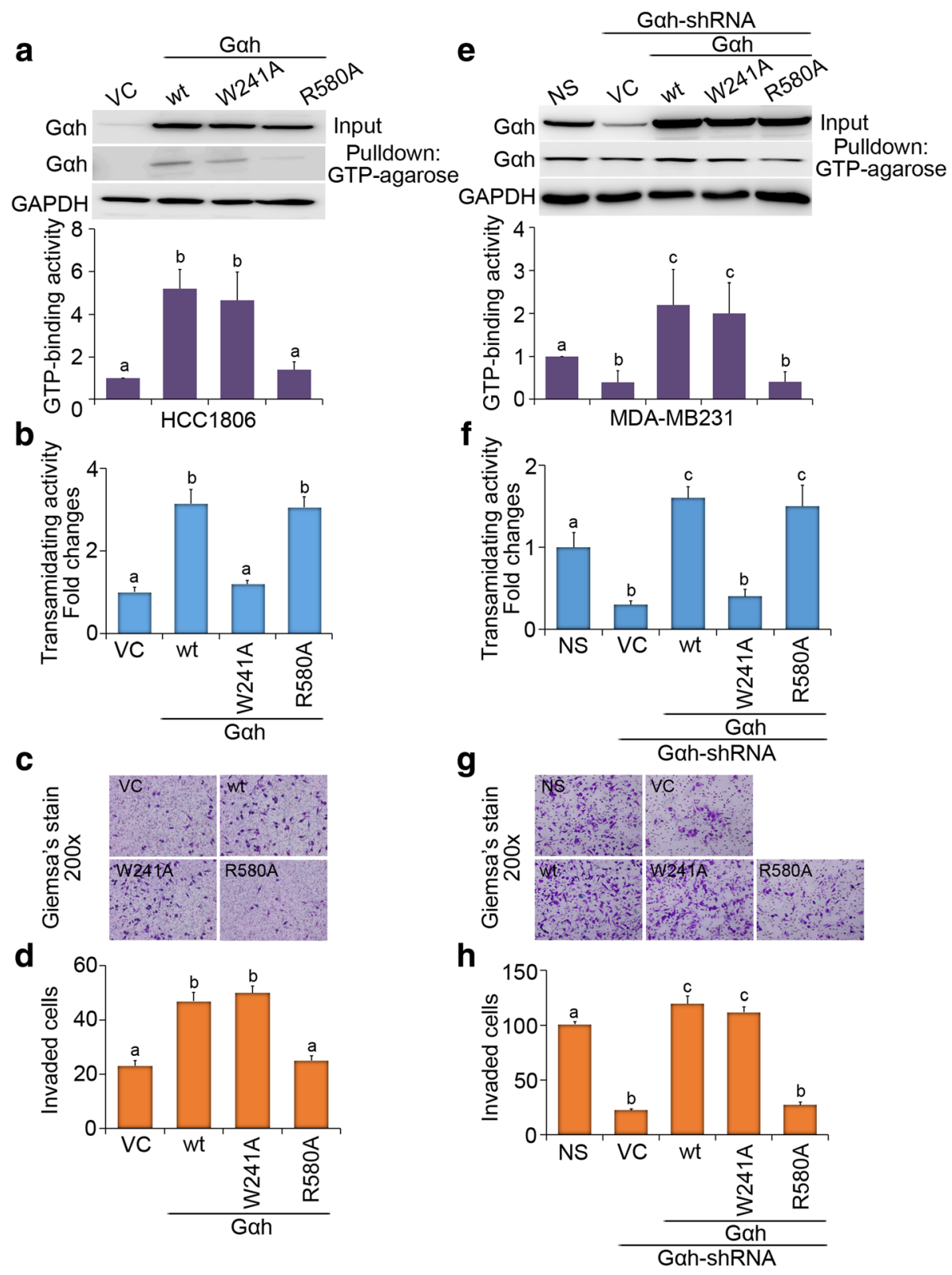

Fig. 3 The GTP-binding, not transamidating, activity of Gah determines the Gah-induced invasiveness of TNBC cells. a Western blot analysis for Gah, GTP-bound Gah, and GAPDH expression in HCC1806 cells transfected with vector control (VC) or exogenous Gah without (wild-type, wt) or with mutations at residues 241 (W to A) and 508 ( $R$ to A). The levels of GTP-bound Gah from three independent experiments were normalized as fold changes relative to VC group and presented as mean \pm SEM (bottom). b Transamidating activity assay of HCC1806 cell variants. $\mathbf{c}$ and $\mathbf{d}$ Giemsa staining $\mathbf{c}$ and quantification $\mathbf{d}$ of invaded cells after $16 \mathrm{~h}$ of incubation of HCC1806 cell variants. e Western blot analysis for Gah, GTP-bound Gah, and GAPDH expression in MDA-MB-231 cells transfected with non-silencing (NS) shRNA or Gah-targeting shRNA followed by restoration of the expression of VC or exogenous wild-type and mutant Gah. The levels of GTP-bound Gah from three independent experiments were shown as fold changes relative to NS group and presented as mean \pm SEM (bottom). $\mathbf{f}$ Transamidating activity assay of MDA-MB-231 cell variants. $\mathbf{g}$ and $\mathbf{h} \mathbf{g}$ Giemsa staining and $\mathbf{h}$ quantification of invaded cells after $16 \mathbf{h}$ of incubation of MDA-MB-231 cell variants. In $\mathbf{a}, \mathbf{b}, \mathbf{d}$, $\mathbf{e}, \mathbf{f}$, and $\mathbf{h}$, different letters above the columns indicate significant differences between the means $(p<0.05)$

Figure S1A and Table S2) [22]. Moreover, the signature of the combination of high cytosolic Gah and high PLC $\delta 1$ appeared to significantly predict a worse outcome in breast cancer patients (Fig. 5h). In addition, the Cox multivariate analysis of disease-free survival indicated that increased PLC 1 level and the signature of high cytosolic Gah/PLC 11 were independent predictive factors of poor outcomes in breast cancer patients (Additional file 1: Figure S1B and Table S4). Notably, the high level of PLC $\delta 1$ and the high cytosolic 

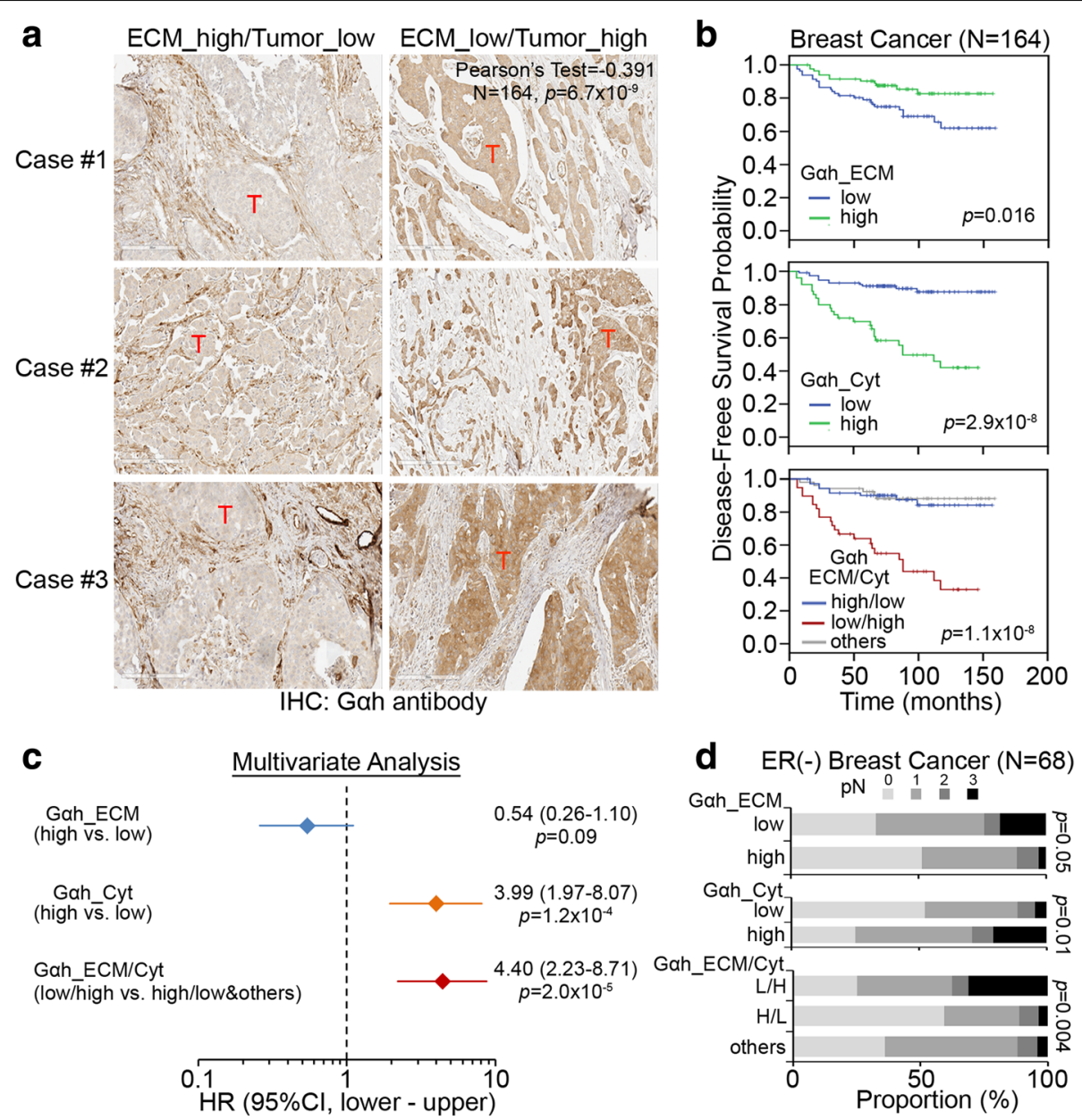

Fig. 4 Clinical significance of extracellular and intracellular Gah. a Representative images of IHC staining for Gah in clinical breast cancer tissues. $T$ denotes tumor regions. $\mathbf{b}$ Kaplan-Meier analysis for extracellular and intracellular Gah levels determined by IHC staining in clinical breast cancer samples with the probability of disease-free survival (DFS). c Multivariate analysis adjusted by $T$ and $\mathrm{N}$ stages for extracellular, intracellular or combined extracellular/intracellular Gah levels using Cox regression test for the probability of DFS in breast cancer patients. $\mathbf{d}$ Correlation of extracellular, intracellular, or combined extracellular/intracellular Gah levels with lymph node metastasis in ER-negative breast cancer

Gah/PLC $\delta 1$ signature correlated with higher pathologic and $\mathrm{N}$ stage in ER-negative breast cancer patients (Fig. 5i). These results highlight the therapeutic value of targeting

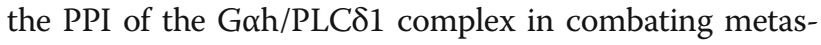
tasis of TNBC.

To validate the therapeutic utility of disrupting the PPI between Goh and PLC $\delta 1$ to suppress TNBC metastasis, we next generated an orthotropic mouse model with luciferase-expressing MDA-MB-231 cells (Fig. 6a). Our data showed that administration of Myr-PLC 1 compared to that of the control peptide robustly inhibited distant lung metastasis (Fig. 6a, b) accompanied with a reduced tumor growth (Fig. 6b) of MDA-MB-231 cells at the primary site in tumor-bearing mice 3 weeks posttreatment. Moreover, histological analysis revealed that the formation of tumor colonies in the lungs was clearly suppressed in the orthotropic mouse model of breast cancer after the treatment with Myr-PLC $\delta 1$ peptide compared to that with the control peptide for 3 weeks (Fig. 6c, d). Significantly, in comparison with the control groups, the administration of Myr-PLC $\delta 1$ peptide appeared to reduce tumor weight at the end of treatment (Fig. 6e). Therefore, the PPI of the Goh/PLC $\delta 1$ complex is not only critical for relaying TNBC metastasis but also serves as a useful target for developing anti-cancer agents against metastatic TNBCs.

\section{Discussion}

The oncogenic role of extracellular and cytosolic Gah in promoting cancer progression is still controversial. The increased levels of extracellular Goh have been shown to promote breast cancer metastasis by recruiting integrinrelated signaling cascades $[10,23]$. Similar findings were found in ovarian cancer where extracellular Goh promotes metastasis via activating the NF- $\mathrm{KB}$ signaling axis [24]. Conversely, here, we show that the increased levels 


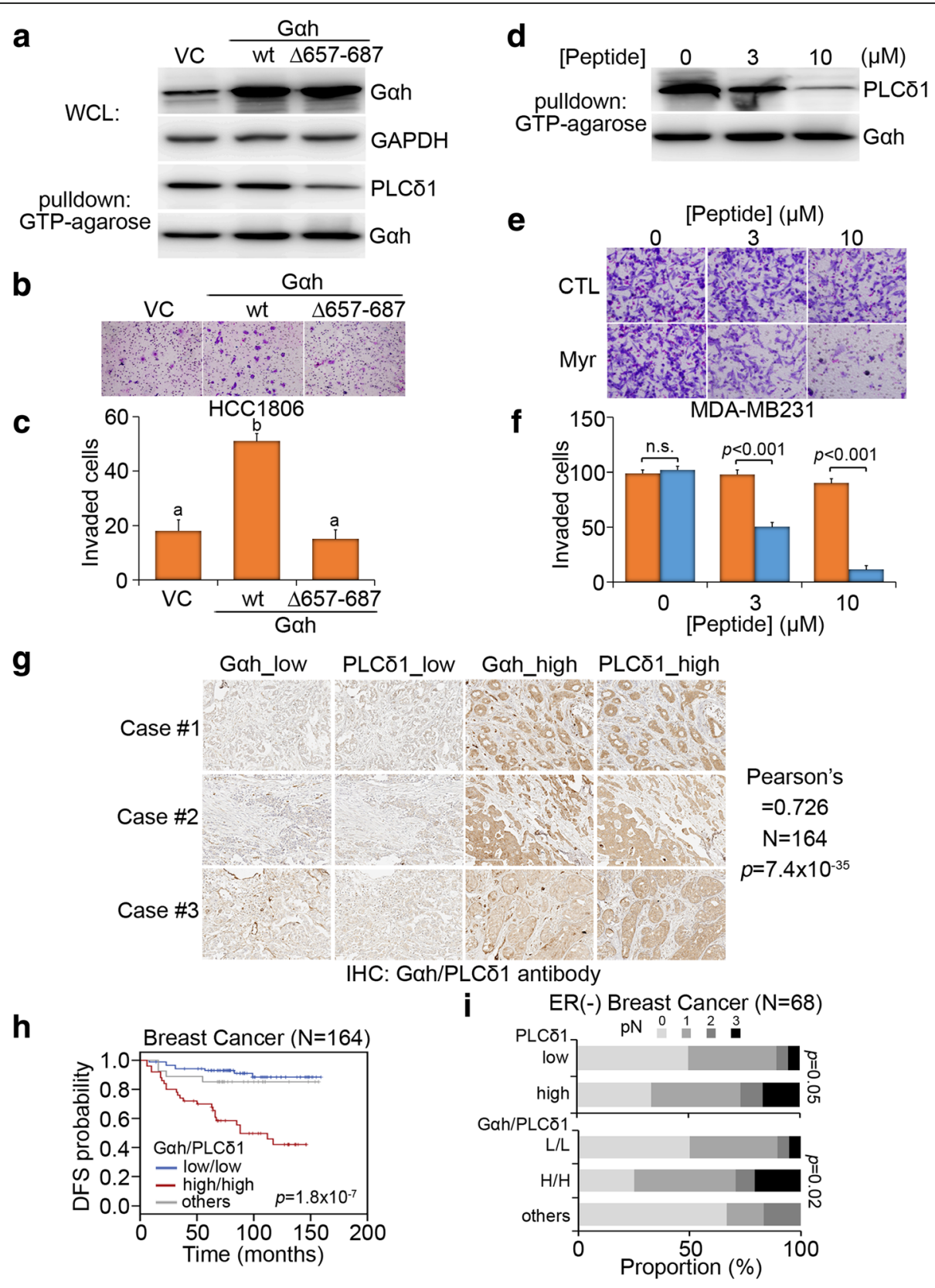

Fig. 5 The protein-protein interaction between Gah and PLC- $\delta 1$ regulates the invasive ability of TNBC cells and serves as a poor prognostic marker in breast cancer patients. a A schematic representation for the construction of the PLC- $\delta 1$-binding site deletion mutant of the Gah protein. $\mathbf{b}$ and $\mathbf{c}$ Giemsa staining $\mathbf{b}$ and quantification (c) of the invaded $\mathrm{H} 1806$ cells after $16 \mathrm{~h}$ of transfection with empty vector (VC) or plasmid expressing wild-type (wt) or deletion-mutant ( $\Delta 657-687)$ Gah. In $\mathbf{c}$, different letters above the columns indicate significant differences between the means $(p<0.05)$. $\mathbf{d}$ Demonstration of the synthesis of the myristoylated (Myr) PLC- $\delta 1$ peptide. e and $\mathbf{f} \mathbf{e}$ Giemsa staining and $\mathbf{f}$ quantification of invaded MDA-MB-231 cells treated with non-Myr (control, CTL, and orange column) or Myr-PLC- $\delta 1$ (blue column) peptide at the designated concentrations for $16 \mathrm{~h}$. g IHC staining for Gah and PLC- $\delta 1$ with their specific antibodies in breast cancer tissues. $\mathbf{h}$ Kaplan-Meier analysis of the Gah/PLC- $\delta 1$ signature and the probability of DFS in breast cancer patients. $\mathbf{i}$ Correlation of PLC- $\delta 1$ or the Gah/PLC- $\delta 1$ signature with lymph node metastasis in ER-negative breast cancer. In $\mathbf{c}$ and $\mathbf{f}$, the data from three independent experiments were presented as the mean $\pm \mathrm{SEM}$

of extracellular Gah refers to a favorable prognosis in breast cancer patients. Similarly, an increased level of extracellular Goh was previously shown to inhibit tumor invasion in TNBCs [25]. Moreover, our data showed that the loss of the transamidating, but not $G$ protein, function of $G \alpha h$ is capable of rescuing the reduced invasive ability in Goh-silenced MDA-MB-231 cells. Similarly, it has been demonstrated that the catalytically

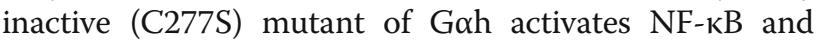
induces HIF-1 $\alpha$ expression as effectively as wild-type 

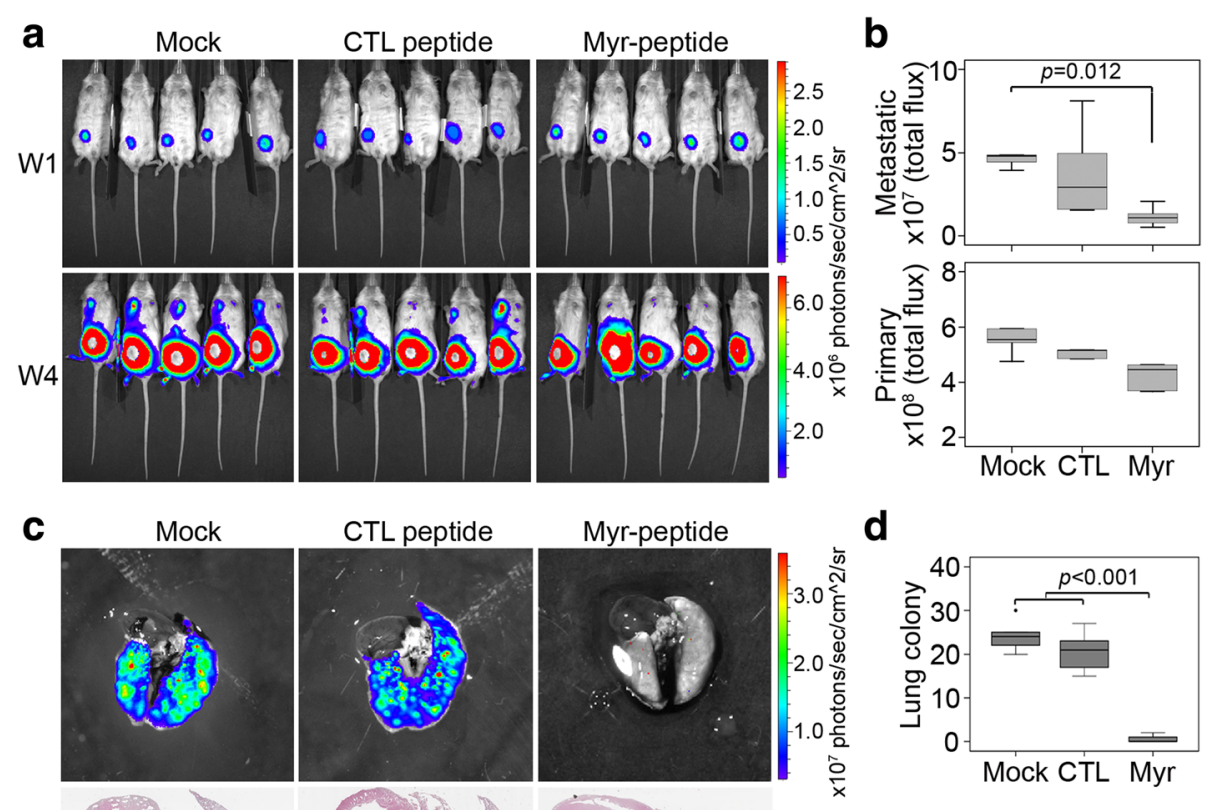

d
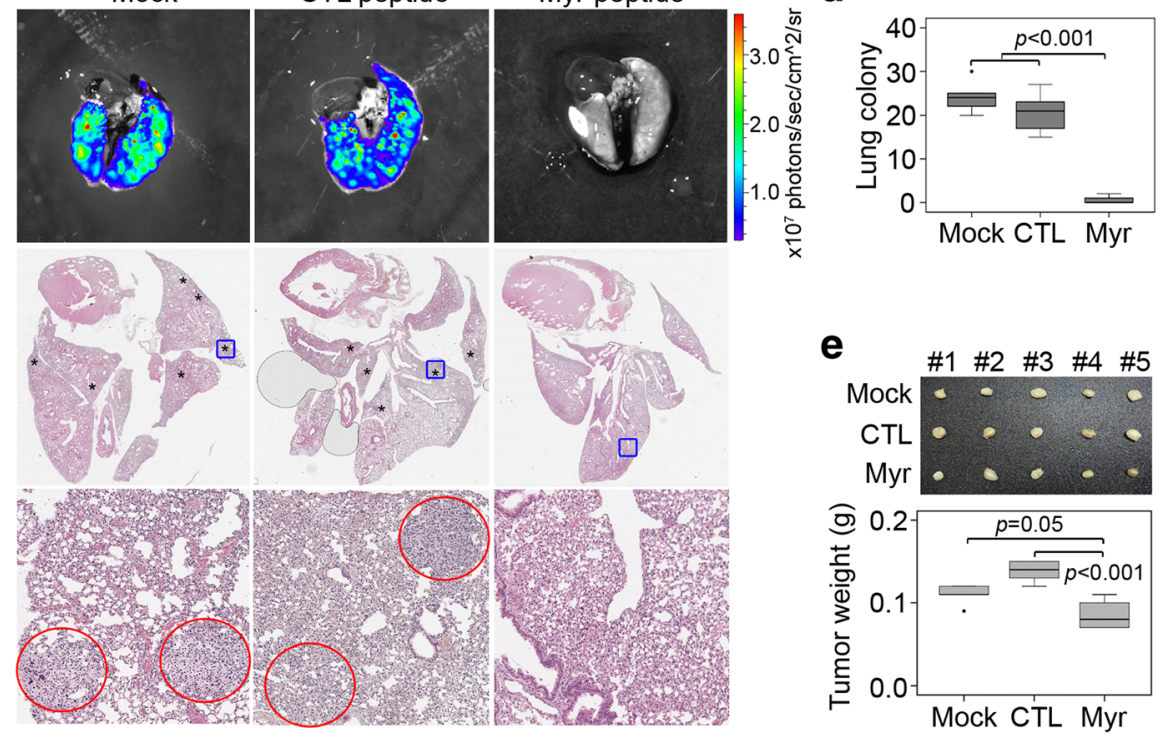

Fig. 6 Therapeutic effectiveness of targeting the PPI of Gah/PLC- $\delta 1$ by Myr-PLC- $\delta 1$ peptide in the orthotropic mouse model of breast cancer. $\mathbf{a}$ and $\mathbf{b}$ The luminescence intensity of luciferase-expressing MDA-MB-231 cells on weeks 1 and 4 after the orthotropic transplantation into mammary fat pads mice (a). Mice $(n=5)$ were treated without [PBS containing $0.1 \%$ TFA (Mock)] or with CTL or Myr-PLC- $\delta 1$ peptide on week 1. b Luminescence intensities of the total flux of protons in the metastatic sites and primary tumors in each group were presented as the median \pm SD. c The representative luminescent images (upper panel) and IHC staining images (middle and lower panels) of lungs from each group at the endpoint. $\mathbf{d}$ Quantitation of the lung colonies in c. e Size and weight of primary tumors obtained from each group on week 4 . The tumor weights are presented as the median \pm SD. In $\mathbf{b}$, d , and $\mathbf{e}$, significant differences were analyzed by one-way ANOVA using Tukey's test

Goh [26]. Since secreted Goh has been thought to be responsible for catalyzing the crosslinking of ECM proteins via its transamidating activity [10], our findings suggest that extracellular Goh likely functions as a tumor suppressor in TNBCs.

Here, we show that the pronounced accumulation of Gah in the cytoplasm predicts worse prognosis and causally associates with the expression of PLC- $\delta 1$ in breast cancer. The loss of both the $\mathrm{G}$ protein function of Gah and its PLC- $\delta 1$ interacting domain reduces the Gah-enhanced metastatic potential of TNBC cells. Previous studies have shown that activation of the Goh/ PLC- $\delta 1$ signaling axis by several G protein-coupled receptors (e.g., $\alpha 1 \mathrm{~B}$-adrenergic [5], oxytocin [27], and FSH [6] receptors) induces fluctuations in the levels of intracellular $\mathrm{Ca}^{2+}$ and promotes the metastatic evolution of TNBC cells by modulating their epithelialto-mesenchymal transition (EMT), which is known as the initial step of cancer metastasis [28, 29]. Notably, the activation of FSH receptor has been shown to induce EMT by triggering the PI3K/Akt-Snail signaling pathway in ovarian cancer cells [30] and to enhance cellular migration and invasion by modulating actin cytoskeleton activity in breast cancer cells [31]. Accordingly, the activation of oxytocin receptor has been found to elevate the invasive properties of endometrial cancer cells via the PI3K/Akt axis [32] and to promote the migratory ability of prostate cancer cells by coupling to the Gi-dependent pathway [33]. These findings implicate the possible role of the $G \alpha h / P L C-\delta 1$ signaling axis in 
these events since the activation of the G $\alpha \mathrm{h} / \mathrm{PLC}-\delta 1$ pathway has been identified to elicit intracellular $\mathrm{Ca}^{2+}$ elevation, promote IP3 turnover, and modulate myosin and actin dynamics [34].

Several studies have demonstrated that Goh-OE correlates with metastatic progression [35-39] as well as drug resistance $[40,41]$ in different types of cancer, suggesting that the discovery of inhibitors of PPI in the Goh/PLC$\delta 1$ complex could be a novel and useful strategy to combat malignant tumors. Although therapeutic targeting of the PPI of Gah/PLC- $\delta 1$ is likely to be effective in treating metastatic TNBCs, further experiments are still needed to identify the Gah-coupled receptor(s) and related signaling cascades in TNBC cells.

\section{Conclusions}

Our data delineated the inverse prognostic values of extracellular and cytoplasmic Goh and validated that the G-protein activity of Goh is crucial for promoting TNBC metastasis by recruiting the PLC- $\delta 1$-associated signaling axis. Blocking the PPI between Goh and PLC- $\delta 1$ displayed an inhibitory effect on the metastatic capacity of TNBC cells in vitro and in vivo, providing a new avenue for drug discovery in cancer.

\section{Additional file}

Additional file 1: Table S1. The paired primers used in the study. Table S2. Cox univariate analysis of disease-free survival for the protein of cytosol Gah [Gah (C)], extracellular Gah [Gah (E)] and PLC- $\delta 1$ and the stage of pathologic T and N. Table S3. Cox multivariate analysis of disease-free survival for the protein of $\mathrm{Gah}(\mathrm{C})$ and $\mathrm{Gah}(\mathrm{E})$ and the stage of pathologic $T$ and N. Table S4. Cox multivariate analysis of disease-free survival for the protein of Gah (C) and PLC- $\delta 1$ and the stage of pathologic T and N. Figure S1. Clinical relevance of Gah and PLC- $\delta 1$ in breast cancer patients. (DOCX $223 \mathrm{~kb}$ )

\section{Acknowledgements}

We like to thank Tzu-Ling Ting for the technical assistance.

\section{Funding}

This study was supported by Ministry of Science and Technology (MOST 104-2320-B-038-061-MY3) and by Taipei Medical University (TMU103-AE1-B13) to Dr. Yuan-Feng Lin.

\section{Availability of data and materials}

Not applicable.

\begin{abstract}
Authors' contributions
SPH, CLC, and YFL contributed to conceptualization and design. SPH, PYL CJK, CLC, WJL, and YFL helped in the development of methodology. SPH, PYL, CJK, CLC, WJL, YHT, and YFL helped in the acquisition of data (provided animals, acquired and managed patients, provided facilities, etc.). SPH, PYL, CLC, and YFL analyzed and interpretated the data (e.g., statistical analysis, biostatistics, and computational analysis). SPH, CJK, CLC, and YFL wrote, reviewed, and/or revised the manuscript. CJK and CLC performed the administrative, technical, or material support (i.e., reporting or organizing data and constructing databases). CLC and YFL supervised the study. All authors read and approved the final manuscript.
\end{abstract}

\section{Competing interests}

The authors declare that they have no competing interests.
Consent for publication

Not applicable.

\section{Ethics approval}

The experiments were approved by Institutional Review Board (IRB) (TMU-IRB 99049) of Taipei Medical University.

\section{Publisher's Note}

Springer Nature remains neutral with regard to jurisdictional claims in published maps and institutional affiliations.

\section{Author details}

${ }^{1}$ Graduate Institute of Clinical Medicine, College of Medicine, Taipei Medical University, 250 Wu-Hsing Street, 110 Taipei, Taiwan. ${ }^{2}$ Department of Veterinary Medicine, National Chung Hsing University, Taichung, Taiwan. ${ }^{3}$ Department of Pathology, Wan Fang Hospital, Taipei Medical University, Taipei, Taiwan. ${ }^{4}$ Department of Urology, School of Medicine, Taipei Medical University, Taipei, Taiwan. ${ }^{5}$ Department of Medical Education and Research, Wan Fang Hospital, Taipei Medical University, Taipei, Taiwan. ${ }^{6}$ Graduate Institute of Medical Sciences, College of Medicine, Taipei Medical University, Taipei, Taiwan.

Received: 10 March 2017 Accepted: 25 May 2017

Published online: 02 June 2017

\section{References}

1. Yadav BS, Sharma SC, Chanana P, Jhamb S. Systemic treatment strategies for triple-negative breast cancer. World J Clin Oncol. 2014;5:125-33.

2. Liedtke C, Bernemann C, Kiesel L, Rody A. Genomic profiling in triple-negative breast cancer. Breast Care (Basel). 2013;8:408-13.

3. Hirshfield KM, Ganesan S. Triple-negative breast cancer: molecular subtypes and targeted therapy. Curr Opin Obstet Gynecol. 2014;26:34-40.

4. Park D, Choi SS, Ha KS. Transglutaminase 2: a multi-functional protein in multiple subcellular compartments. Amino Acids. 2010;39:619-31.

5. Feng JF, Gray CD, Im MJ. Alpha 1B-adrenoceptor interacts with multiple sites of transglutaminase I: characteristics of the interaction in binding and activation. Biochemistry. 1999;38:2224-32.

6. Lin YF, Tseng MJ, Hsu HL, Wu YW, Lee YH, Tsai YH. A novel follicle-stimulating hormone-induced $\mathrm{G}$ alpha h/phospholipase C-delta1 signaling pathway mediating rat sertoli cell Ca2 + -influx. Mol Endocrinol. 2006;20:2514-27.

7. Lai TH, Lin YF, Wu FC, Tsai YH. Follicle-stimulating hormone-induced Galphah/phospholipase C-delta1 signaling mediating a noncapacitative Ca2+ influx through T-type Ca2+ channels in rat sertoli cells. Endocrinology. 2008;149:1031-7.

8. Azimi I, Roberts-Thomson SJ, Monteith GR. Calcium influx pathways in breast cancer: opportunities for pharmacological intervention. $\mathrm{Br}$ J Pharmacol. 2014;171:945-60.

9. Salt MB, Bandyopadhyay S, McCormick F. Epithelial-to-mesenchymal transition rewires the molecular path to PI3K-dependent proliferation. Cancer Discov. 2014:4:186-99.

10. Agnihotri N, Kumar S, Mehta K. Tissue transglutaminase as a central mediator in inflammation-induced progression of breast cancer. Breast Cancer Res. 2013;15:202.

11. Mehta K, Fok J, Miller FR, Koul D, Sahin AA. Prognostic significance of tissue transglutaminase in drug resistant and metastatic breast cancer. Clin Cancer Res. 2004;10:8068-76.

12. Assi J, Srivastava G, Matta A, Chang MC, Walfish PG, Ralhan R. Transglutaminase 2 overexpression in tumor stroma identifies invasive ductal carcinomas of breast at high risk of recurrence. PLoS One. 2013;8:e74437.

13. Miyoshi N, Ishii H, Mimori K, Tanaka F, Hitora T, Tei M, Sekimoto M, Doki Y, Mori M. TGM2 is a novel marker for prognosis and therapeutic target in colorectal cancer. Ann Surg Oncol. 2010;17:967-72.

14. Satpathy M, Cao L, Pincheira R, Emerson R, Bigsby R, Nakshatri H, Matei D. Enhanced peritoneal ovarian tumor dissemination by tissue transglutaminase. Cancer Res. 2007;67:7194-202.

15. Choi CM, Jang SJ, Park SY, Choi YB, Jeong JH, Kim DS, Kim HK, Park KS, Nam $\mathrm{BH}$, Kim HR, Kim SY, Hong KM. Transglutaminase 2 as an independent prognostic marker for survival of patients with non-adenocarcinoma subtype of non-small cell lung cancer. Mol Cancer. 2011;10:119.

16. Erdem S, Yegen G, Telci D, Yildiz I, Tefik T, Issever H, Kilicaslan I, Sanli O. The increased transglutaminase 2 expression levels during initial tumorigenesis 
predict increased risk of metastasis and decreased disease-free and cancerspecific survivals in renal cell carcinoma. World J.Urol. 2015;33(10):1553-60.

17. Kumar A, Xu J, Sung B, Kumar S, Yu D, Aggarwal BB, Mehta K. Evidence that GTP-binding domain but not catalytic domain of transglutaminase 2 is essential for epithelial-to-mesenchymal transition in mammary epithelial cells. Breast Cancer Res. 2012;14:R4.

18. Ho SN, Hunt HD, Horton RM, Pullen JK, Pease LR. Site-directed mutagenesis by overlap extension using the polymerase chain reaction. Gene. 1989;77: $51-9$.

19. Mizuno H, Kitada K, Nakai K, Sarai A. PrognoScan: a new database for metaanalysis of the prognostic value of genes. BMC Med Genomics. 2009;2:18.

20. Zhu J, Sanborn JZ, Benz S, Szeto C, Hsu F, Kuhn RM, Karolchik D, Archie J, Lenburg ME, Esserman LJ, Kent WJ, Haussler D, Wang T. The UCSC Cancer Genomics Browser. Nat Methods. 2009;6:239-40.

21. Feng JF, Rhee SG, Im MJ. Evidence that phospholipase delta1 is the effector in the Gh (transglutaminase II)-mediated signaling. J Biol Chem. 1996;271: 16451-4.

22. Cai S, Sun PH, Resaul J, Shi L, Jiang A, Satherley LK, Davies EL, Ruge F, Douglas-Jones A, Jiang WG, Ye L. Expression of phospholipase C isozymes in human breast cancer and their clinical significance. Oncol Rep. 2017;37: 1707-15.

23. Nurminskaya MV, Belkin AM. Cellular functions of tissue transglutaminase. Int Rev Cell Mol Biol. 2012;294:1-97.

24. Yakubov B, Chelladurai B, Schmitt J, Emerson R, Turchi JJ, Matei D. Extracellular tissue transglutaminase activates noncanonical NF-kappaB signaling and promotes metastasis in ovarian cancer. Neoplasia. 2013;15:609-19.

25. Mangala LS, Arun B, Sahin AA, Mehta K. Tissue transglutaminase-induced alterations in extracellular matrix inhibit tumor invasion. Mol Cancer. 2005;4:33.

26. Kumar S, Mehta K. Tissue transglutaminase constitutively activates HIF1alpha promoter and nuclear factor-kappaB via a non-canonical pathway. PLoS One. 2012;7:e49321.

27. Baek KJ, Kwon NS, Lee HS, Kim MS, Muralidhar P, Im MJ. Oxytocin receptor couples to the $80 \mathrm{kDa}$ Gh alpha family protein in human myometrium. Biochem J. 1996:315(Pt 3):739-44

28. Hu J, Qin K, Zhang Y, Gong J, Li N, Lv D, Xiang R, Tan X. Downregulation of transcription factor Oct4 induces an epithelial-to-mesenchymal transition via enhancement of $\mathrm{Ca} 2+$ influx in breast cancer cells. Biochem Biophys Res Commun. 2011:411:786-91.

29. Davis FM, Peters AA, Grice DM, Cabot PJ, Parat MO, Roberts-Thomson SJ, Monteith GR. Non-stimulated, agonist-stimulated and store-operated Ca2+ influx in MDA-MB-468 breast cancer cells and the effect of EGF-induced EMT on calcium entry. PLoS One. 2012;7:e36923.

30. Yang Y, Zhang J, Zhu Y, Zhang Z, Sun H, Feng Y. Follicle-stimulating hormone induced epithelial-mesenchymal transition of epithelial ovarian cancer cells through follicle-stimulating hormone receptor PI3K/Akt-Snail signaling pathway. Int J Gynecol Cancer. 2014;24:1564-74.

31. Sanchez AM, Flamini MI, Russo E, Casarosa E, Pacini S, Petrini M, Genazzani AR, Simoncini T. LH and FSH promote migration and invasion properties of a breast cancer cell line through regulatory actions on the actin cytoskeleton. Mol Cell Endocrinol. 2016;437:22-34.

32. Dery MC, Chaudhry P, Leblanc V, Parent S, Fortier AM, Asselin E. Oxytocin increases invasive properties of endometrial cancer cells through phosphatidylinositol 3-kinase/AKT-dependent up-regulation of cyclooxygenase-1, -2 , and X-linked inhibitor of apoptosis protein. Biol Reprod. 2011:85:1133-42

33. Zhong M, Boseman ML, Millena AC, Khan SA. Oxytocin induces the migration of prostate cancer cells: involvement of the Gi-coupled signaling pathway. Mol Cancer Res. 2010;8:1164-72.

34. Lin YF, Yeh TS, Chen SF, Tsai YH, Chou CM, Yang YY, Huang HM. Nonmuscle myosin IIA (myosin heavy polypeptide 9): a novel class of signal transducer mediating the activation of $\mathrm{G}$ alpha h/phospholipase C-delta 1 pathway. Endocrinology. 2010;151:876-85.

35. Erdem S, Yegen G, Telci D, Yildiz I, Tefik T, Issever H, Kilicaslan I, Sanli O. The increased transglutaminase 2 expression levels during initial tumorigenesis predict increased risk of metastasis and decreased disease-free and cancer-specific survivals in renal cell carcinoma. World J Urol. 2015;33:1553-60

36. Verma A, Guha S, Diagaradjane $P$, Kunnumakkara AB, Sanguino AM, Lopez-Berestein G, Sood AK, Aggarwal BB, Krishnan S, Gelovani JG, Mehta K. Therapeutic significance of elevated tissue transglutaminase expression in pancreatic cancer. Clin Cancer Res. 2008;14:2476-83.
37. Lee J, Condello S, Yakubov B, Emerson R, Caperell-Grant A, Hitomi K, Xie J, Matei D. Tissue transglutaminase mediated tumor-stroma interaction promotes pancreatic cancer progression. Clin Cancer Res. 2015;21:4482-93.

38. Verma A, Guha S, Wang H, Fok JY, Koul D, Abbruzzese J, Mehta K. Tissue transglutaminase regulates focal adhesion kinase/AKT activation by modulating PTEN expression in pancreatic cancer cells. Clin Cancer Res. 2008;14:1997-2005.

39. Mangala LS, Fok JY, Zorrilla-Calancha IR, Verma A, Mehta K. Tissue transglutaminase expression promotes cell attachment, invasion and survival in breast cancer cells. Oncogene. 2007;26:2459-70.

40. Park KS, Kim HK, Lee JH, Choi YB, Park SY, Yang SH, Kim SY, Hong KM. Transglutaminase 2 as a cisplatin resistance marker in non-small cell lung cancer. J Cancer Res Clin Oncol. 2010;136:493-502.

41. Verma A, Mehta K. Tissue transglutaminase-mediated chemoresistance in cancer cells. Drug Resist Updat. 2007:10:144-51.

\section{Submit your next manuscript to BioMed Central and we will help you at every step:}

- We accept pre-submission inquiries

- Our selector tool helps you to find the most relevant journal

- We provide round the clock customer support

- Convenient online submission

- Thorough peer review

- Inclusion in PubMed and all major indexing services

- Maximum visibility for your research

Submit your manuscript at www.biomedcentral.com/submit
Biomed Central 